\title{
VARIABILITY AND GENETIC DIVERSITY STUDIES ON NEOLAMARCKIA CADAMBA GENETIC RESOURCES
}

\author{
Parthiban KT, Thirunirai-Selvan R*, Palanikumaran B \& Krishnakumar N \\ Forest College and Research Institute, Tamil Nadu Agricultural University, Mettupalayam, Tamilnadu 641301, India \\ *selvanforester@gmail.com
}

Submitted September 2017; accepted June 2018

\begin{abstract}
Agroforestry in India is gaining significance due to increase in demand for wood and wood products and the felling restriction on natural forest resources. However, the agroforestry promotion is detracted due to the availability of high yielding, short rotation varieties amenable for agroforestry. For this purpose, systematic improvement program has been initiated for Neolamarckia cadamba (kadam) genetic resources which is identified as one of the potential fast growing tree species amenable for agroforestry system. Accordingly, 20 progenies of kadam genetic resources were evaluated, and the results on variability and diversity were furnished in this study. The progenies differed significantly which resulted in superiority progeny, FCRIK17, recommended for immediate adoption in the agroforestry system and to incorporate them in future breeding program. The variability studies indicated that volume recorded was maximum followed by height and girth at breast height (gbh). The volume also registered high heritability followed by height and gbh. The genetic diversity studies resolved 20 progenies of kadam into 5 clusters, and the cluster III registered higher intra-cluster distance. The inter-cluster distance was maximum between clu ster I and IV. Among the growth attributes, volume contributed maximum towards genetic divergence. Hence, the higher the volume registered by progeny FCRIK17, followed by higher heritability, addresses the issue of availability of short rotation genetic resources for incorporation in agroforestry program.
\end{abstract}

Keywords: Heritability, genetic advance, growth attributes, cluster composition, agroforestry

\section{INTRODUCTION}

Neolamarkia cadamba (kadam), belonging to the family of Rubiaceae, is an evergreen tree, distributed naturally in India, Nepal through Thailand and Indo-china and eastward in Malaysia to Papua New Guinea. It is successfully introduced in Africa and Central America. Within the natural distribution, it is found below $1000 \mathrm{~m}$ altitude and normally in the areas receiving rainfall more than $1500 \mathrm{~mm}$ year ${ }^{-1}$ but it can also withstand less rainfall of about $200 \mathrm{~mm} \mathrm{year}^{-1}$. It is light demanding, intolerant to frost and can withstand periodic flood.

Kadam is a multipurpose tree with utility of pulp and paper, splints and veneer production. The bark of the plant contains anti-inflammatory, digestive, carminative, constipating and antiemetic properties. The flowers are used as vegetable and raw material for attar production with sandalwood as the base. Leaves are slightly aromatic and the decoction of the leaves are used to cure ulcers, wounds and mettorrhea. The leaves are also used for fodder production due to its low mimosine content.
Kadam is a lightweight hardwood with a density of $290-560 \mathrm{~kg} \mathrm{~m}^{-3}$ at $15 \%$ moisture content. It has a fine to medium texture, straight grain, low luster and has no characteristic odour or taste (Joker 2000). On a very conservative estimate, the yield of $0.4 \mathrm{~m}^{3}$ wood can be easily obtained from a Kadam tree under rotation of 10 years by which time each tree will have a girth varying from $90 \mathrm{~cm}$ to $1 \mathrm{~m}$ (Ho et al. 2012).

Such a multifarious and fast growing species has received little research attention particularly on improvement of the species through systematic tree breeding program. Hence, the current study was designed to improve the species through systematic tree improvement program.

\section{MATERIALS AND METHODS}

The experimental materials for this study consisted of 20 genotypes of kadam selected from various locations in India (Table 1). The seed source evaluation experiments were carried out in the field of Forest College and Research 
Table 1 Details of Neolamarckia cadamba genetic resources and locations

\begin{tabular}{|c|c|c|c|c|c|}
\hline Location & Genotype & State & Latitude & Longitude & Altitude (m) \\
\hline Tripura & FCRIK1 & Tripura & $23^{\circ} 49^{\prime}$ & $91^{\circ} 17^{\prime}$ & 78 \\
\hline Khowai & FCRIK2 & Tripura & $24^{\circ} 04^{\prime}$ & $91^{\circ} 36^{\prime}$ & 46 \\
\hline Tripura & FCRIK3 & Tripura & $23^{\circ} 55^{\prime}$ & $91^{\circ} 50^{\prime}$ & 89 \\
\hline Mettupalayam & FCRIK4 & Tamil Nadu & $11^{\circ} 17^{\prime}$ & $76^{\circ} 56^{\prime}$ & 330 \\
\hline Assam & FCRIK5 & Assam & $26^{\circ} 33^{\prime}$ & $90^{\circ} 26^{\prime}$ & 69 \\
\hline Assam & FCRIK6 & Assam & $26^{\circ} 33^{\prime}$ & $90^{\circ} 26^{\prime}$ & 69 \\
\hline Coimbatore & FCRIK7 & Tamil Nadu & $11^{\circ} 17^{\prime}$ & $76^{\circ} 56^{\prime}$ & 330 \\
\hline Coimbatore & FCRIK8 & Tamil Nadu & $11^{\circ} 17^{\prime}$ & $76^{\circ} 56^{\prime}$ & 330 \\
\hline Coimbatore & FCRIK9 & Tamil Nadu & $11^{\circ} 17^{\prime}$ & $76^{\circ} 56^{\prime}$ & 330 \\
\hline Coimbatore & FCRIK10 & Tamil Nadu & $11^{\circ} 17^{\prime}$ & $76^{\circ} 56^{\prime}$ & 330 \\
\hline Dapoli & FCRIK11 & Maharashtra & $17^{\circ} 45^{\prime}$ & $73^{\circ} 11^{\prime}$ & 175 \\
\hline Maharashtra & FCRIK12 & Maharashtra & $21^{\circ} 08^{\prime}$ & $79^{\circ} 05^{\prime}$ & 313 \\
\hline Tirupathi & FCRIK13 & Andhra Pradesh & $13^{\circ} 37^{\prime}$ & $79^{\circ} 25^{\prime}$ & 155 \\
\hline Andhra Pradesh & FCRIK14 & Andhra Pradesh & $13^{\circ} 37^{\prime}$ & $79^{\circ} 25^{\prime}$ & 155 \\
\hline Hyderabad & FCRIK15 & Andhra Pradesh & $17^{\circ} 22^{\prime}$ & $78^{\circ} 29^{\prime}$ & 502 \\
\hline Andhra Pradesh & FCRIK16 & Andhra Pradesh & $17^{\circ} 22^{\prime}$ & $78^{\circ} 29^{\prime}$ & 502 \\
\hline Karnal & FCRIK17 & Haryana & $29^{\circ} 41^{\prime}$ & $76^{\circ} 59^{\prime}$ & 251 \\
\hline Haryana & FCRIK18 & Haryana & $29^{\circ} 41^{\prime}$ & $76^{\circ} 59^{\prime}$ & 251 \\
\hline Thrissur & FCRIK19 & Kerala & $10^{\circ} 31^{\prime}$ & $79^{\circ} 13^{\prime}$ & 54 \\
\hline Bangalore & FCRIK20 & Karnataka & $12^{\circ} 58^{\prime}$ & $77^{\circ} 35^{\prime}$ & 910 \\
\hline
\end{tabular}

FCRIK1-20 = Neolamarckia cadamba progenies

Institute, Tamil Nadu Agricultural University, Mettupalayam $\left(11^{\circ} 19^{\prime} \mathrm{N}, 76^{\circ} 56^{\prime} \mathrm{E}\right), 300 \mathrm{msl}$, $800 \mathrm{~mm}, \mathrm{pH}$ 7.1) during 2010-2016. Twenty superior progenies were planted in a randomised block design ( $r b d$ ) with four replications and the spacing adopted was $3 \mathrm{~m} \times 3 \mathrm{~m}$. Rainfall, temperature and humidity details during the growing periods of the years under study are given in Table 2.

The observations viz., girth at breast height (gbh), height and volume were recorded on all genotypes at 12 months after planting (12 MAP), 24 months after planting (24 MAP), 36 months after planting (36 MAP), 48 months after planting (48 MAP) and 60 months after planting (60 MAP). The following growth attributes viz., height, gbh and volume were recorded and subjected to genetic analysis.

Variability, heritability and association study

Variability studies were estimated as per the method described by Johnson et al. (1955).

\section{Genotypic variance (GV)}

Genotypic variance $=\frac{\sigma^{2} \mathrm{~g}-\sigma^{2} \mathrm{e}}{\mathrm{r}}$

where $\sigma^{2} \mathrm{~g}=$ genotypic mean square, $\sigma^{2} \mathrm{e}=$ error variance, $r=$ number of replications

\section{Phenotypic variance $(P V)$}

$$
\text { Phenotypic variance }=\sigma^{2} \mathrm{~g}-\sigma^{2} \mathrm{e}
$$

where $\sigma^{2} \mathrm{~g}=$ genotypic variance, $\sigma^{2} \mathrm{e}=$ error variance. Phenotypic (PCV) and genotypic (GCV) coefficients of variances were computed following Burton (1952).

\section{Phenotypic co-efficient of variability}

Phenotypic co-efficient of variability (PVC) was arrived by using the formula as given below

$$
\mathrm{PCV} \%=\frac{\text { Phenotypic variance } \frac{1 / 2}{2}}{\text { General mean }} \times 100
$$


Table 2 Meteorological data during the growing periods

\begin{tabular}{ccccc}
\hline \multirow{2}{*}{ Year } & \multicolumn{2}{c}{ Temperature $\left({ }^{\circ} \mathrm{C}\right)$} & Relative humidity $(\%)$ & Rainfall $(\mathrm{mm})$ \\
\cline { 2 - 3 } & Max. & Min. & 53.09 & 1161.7 \\
2010 & 33.76 & 21.24 & 54.54 & 991.00 \\
2011 & 33.53 & 19.37 & 49.82 & 643.00 \\
2012 & 34.14 & 20.38 & 50.57 & 781.60 \\
2013 & 34.12 & 21.04 & 48.96 & 1132.00 \\
2014 & 34.13 & 20.98 & 52.10 & 1139.00 \\
2015 & 33.48 & 21.07 & & \\
\hline
\end{tabular}

\section{Genotypic co-efficient of variability}

Genotypic co-efficient of variability (GCV) was arrived by using the formula as given below

$$
\text { GCV } \%=\frac{\text { Genotypic variance }{ }^{1 / 2}}{\text { General mean }} \times 100
$$

\section{Heritability $\left(h^{2}\right)$}

Broad sense heritability $\left(\mathrm{h}^{2}\right)$ was calculated according to Lush (1940)

$$
\mathrm{h}^{2}=\frac{\sigma^{2} \mathrm{~g}}{\sigma^{2} \mathrm{p}}
$$

Heritability percentage $=\mathrm{h}^{2} \times 100$

\section{Genetic advance}

Genetic advance will be worked out after Johnson et al. (1955) .

$$
\text { Genetic advance }=\frac{\text { Genotypic Variance }}{\text { Pheotypic vvariance }^{1 / 2}} \times \mathrm{K}
$$

where $\mathrm{K}=2.06$, a selection differential at $5 \%$ selection intensity.

\section{Determination of genetic divergence}

The $\mathrm{D}^{2}$ statistics are adopted for the estimation of genetic divergence (Mahalanobis 1928). Using $\mathrm{D}^{2}$ statistical results, the clustering of progenies was done.

\section{RESULTS}

\section{Growth performance}

The progenies differed significantly for all growth attributes investigated of all growth periods. Twenty progenies differed significantly at 48 MAP and 60 MAP for tree height. In 60 MAP, FCRIK17 $(8.43 \mathrm{~m})$ registered higher tree height followed by FCRIK19 (8.21 m), FCRIK1 (7.95 m), FCRIK5 $(7.85 \mathrm{~m})$ and FCRIK14 $(7.64 \mathrm{~m})$ compared to general mean $(6.46 \mathrm{~m})$ at $5 \%$ significance level (Table 3).

The gbh differed significantly at 60 MAP and two progenies viz., FCRIK17 $(45.43 \mathrm{~cm})$ and FCRIK19 $(44.93 \mathrm{~cm})$ have shown higher gbh (Table 3). Among the 20 progenies, two progenies viz., FCRIK17 $\left(0.145 \mathrm{~m}^{3}\right)$ and FCRIK19 $\left(0.138 \mathrm{~m}^{3}\right)$ recorded significantly higher volume growth compared to general mean $\left(0.081 \mathrm{~m}^{3}\right)$ at $5 \%$ level of significance (Table 3 ).

\section{Variability and heritability parameters}

The tree height exercised moderate phenotypic and low genotypic coefficient of variations of 24.11 and 14.27 percent respectively. The phenotypic and genotypic coefficient of variations for gbh was low viz., 19.74 and $14.04 \%$ respectively. The volume recorded maximum PCV (56.23) and GCV (40.53) compared to other parameters.

Tree height, gbh and volume recorded a moderate heritability of $0.35,0.50$ and $0.51 \%$ respectively. Tree height registered low genetic advance, as percent of mean, was 17.40 and moderate genetic advance, as percent of mean, was 20.57, recorded for GBH. The genetic advance as percent of mean recorded by volume was 60.18 which was maximum among all traits. (Table 4).

\section{Determination of genetic diversity}

\section{Genetic divergence}

The mean values were transformed into standardised uncorrelated mean values. The $\mathrm{D}^{2}$ values were computed for all positive pairs. 20 accessions of Kadam were placed under five 


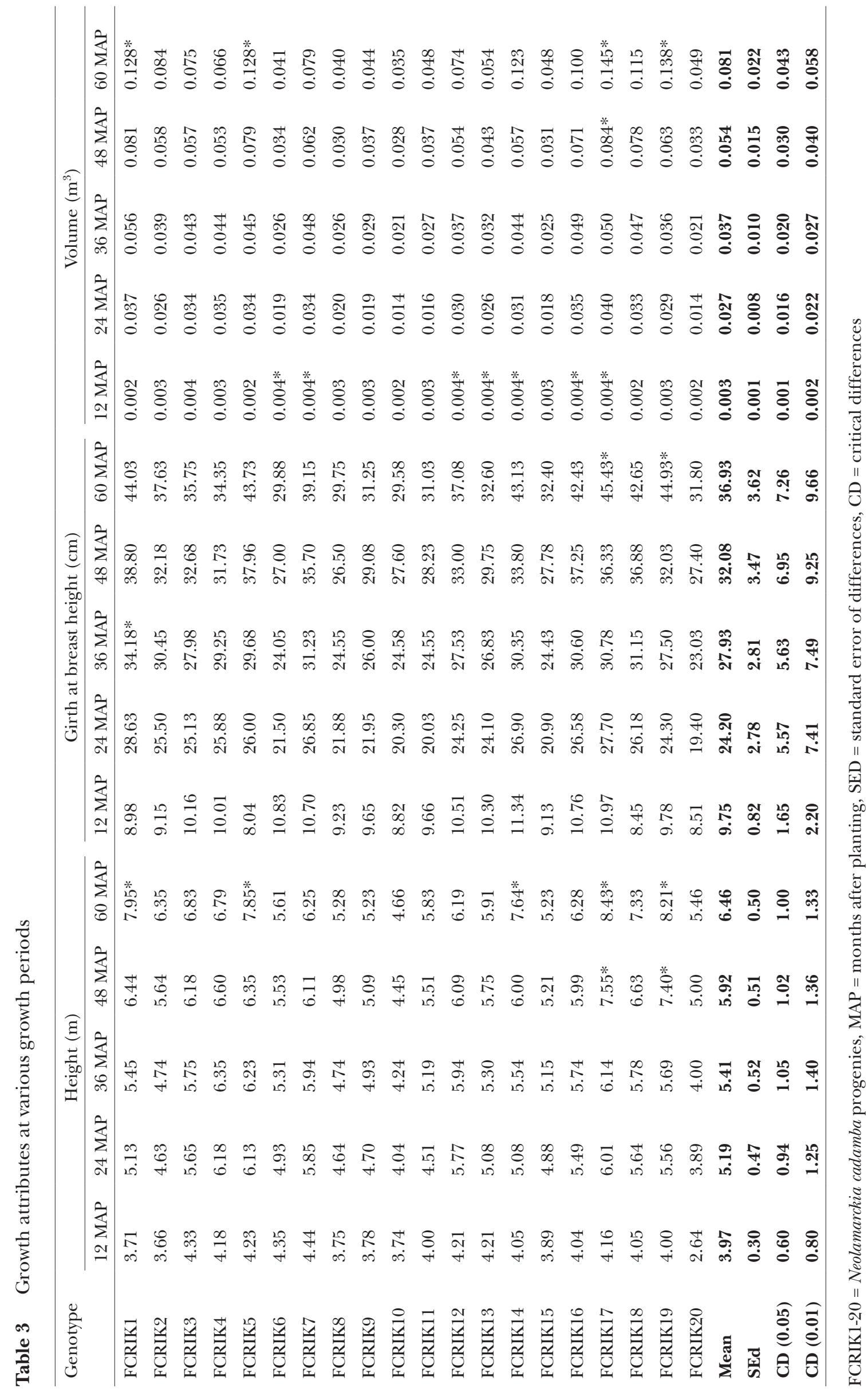


Table 4 Genetic parameters for growth traits among Neolamarckia cadamba

\begin{tabular}{lcccc}
\hline Character & GCV & PCV & Heritability & GA $(\%)$ of Mean \\
\hline Height & 14.27 & 24.11 & 0.3502 & 17.40 \\
Girth at Breast Height & 14.04 & 19.74 & 0.5057 & 20.57 \\
Volume & 40.53 & 56.23 & 0.5195 & 60.18 \\
\hline
\end{tabular}

GCV = genotypic co-efficient of variability, PCV = phenotypic co-efficient of variability, GA = genetic advance

clusters on the basis of Mahalanobis $\mathrm{D}^{2}$ clustering techniques.

\section{Cluster components}

The clustering pattern revealed that the 20 progenies were resolved into five different clusters. Cluster I constituted of 2 progenies, FCRIK8 and FCRIK10, cluster II consisted of 2 progenies, FCRIK15 and FCRIK20, cluster III consisted of 6 progenies, FCRIK1, FCRIK2, FCRIK3, FCRIK4, FCRIK5 and FCRIK19, cluster IV consisted of 6 progenies, FCRIK6, FCRIK7, FCRIK9, FCRIK11, FCRIK12 and FCRIK13, and cluster V consisted of 4 progenies, FCRIK14, FCRIK16, FCRIK17 and FCRIK18 (Table 5).

\section{Intra- and inter-cluster average distance}

The average inter- and intra-cluster $\mathrm{D}^{2}$ and $\mathrm{D}$ values among the five clusters are presented in Table 6. Intra- and inter-cluster ranged from 0.01 to 2.32 and 0.45 to 9.75 respectively. Intra-cluster distance was maximum in cluster III (2.32) with six accessions and minimum in cluster I with one accession. Highest inter-cluster was between cluster I and V (9.75), followed by cluster I and III (7.30) suggesting that there is a wide genetic diversity between these groups. The minimum inter-cluster distance was between cluster I and II $(0.45)$.

\section{Cluster mean performance}

The cluster mean for the traits was estimated and furnished in Table 7. Cluster mean expressed significant variation among the clusters for all traits. The members in cluster $\mathrm{V}$ showed the highest performance of 7.38 for tree height followed by cluster III (7.26) while, the minimum was observed for cluster I (4.84). The maximum cluster mean of 43.41 was observed for gbh in cluster IV whereas the least cluster mean for gbh (29.76) was exhibited by cluster I. In case of volume, the cluster mean was highest for cluster V (0.118) and the lowest for cluster I (0.037). In general, cluster $\mathrm{V}$ and cluster I had highest and lowest mean values for most of the traits respectively.

\section{Contribution of characters towards genetic divergence}

The number of times each character ranking first was counted and percentage contribution towards divergence were calculated and presented in Table 8. Volume contributed maximum percentage towards divergence $(57.90 \%)$ followed by height (25.26\%). Contribution towards divergence was least in gbh (16.84\%).

\section{DISCUSSION}

\section{Growth performance}

The progeny test showed significant differences among 20 progenies of Kadam for growth attribute viz., height, gbh and volume at 12 , 24, 36, 48 and 60 MAP. Significant variation was found in all growth characteristics viz., tree height, gbh and volume among 20 progenies. Considering all the 20 progenies, the superiority of FCRIK17 progeny was consistent. A plethora of workers reported the existence of significant differences and superiority of few seed sources, progenies and provenances in various trees such as Azadirachta indica (Syed et al. 2013), Populus deltoides (Jha 2012), Gmelina arborea (Kumar 2007) Eucalyptus tereticornis (Ginwal et al. 2004) and Dalbergia sissoo (Tewari et al. 1996) which lend support to the result of current study.

Similarly, Teak provenance exhibited variation in growth characteristics (Rawat et al. 1998, Rao et al. 2001). Significant variation in height, girth and number of internodes were also reported in teak progeny evaluation (Lakshmikantham et al. 1974). The provenance from konni of kerala exhibited best score for growth characters (Rao 
Table 5 Composition of clusters for growth traits among Neolamarckia cadamba

\begin{tabular}{cl}
\hline Cluster No & \multicolumn{1}{c}{ Members } \\
\hline I & FCRIK8, FCRIK10 \\
II & FCRIK15, FCRIK 20 \\
III & FCRIK1, FCRIK2, FCRIK3, FCRIK4, FCRIK5, FCRIK19 \\
IV & FCRIK6, FCRIK7, FCRIK9, FCRIK11, FCRIK12, FCRIK13 \\
V & FCRIK14, FCRIK16, FCRIK17, FCRIK18 \\
\hline
\end{tabular}

FCRIK = Neolamarckia cadamba progenies

Table 6 Estimates of inter- and intra-cluster distances for growth traits in Neolamarckia cadamba (Kadam)

\begin{tabular}{cccccc}
\hline & I & II & III & IV & V \\
\hline I & $0.0073(0.0857)$ & $0.4540(0.6738)$ & $7.3016(2.7021)$ & $1.8089(1.3449)$ & $9.7522(3.1229)$ \\
II & & $0.0660(0.2569)$ & $4.7866(2.1878)$ & $0.8271(0.9095)$ & $6.6076(2.5705)$ \\
III & & & $2.3243(1.5246)$ & $3.9401(1.9850)$ & $1.9213(1.3861)$ \\
IV & & & & $1.4277(1.1949)$ & $5.4373(2.3318)$ \\
V & & & & & $1.3789(1.1743)$ \\
\hline
\end{tabular}

Table 7 Cluster mean value for growth traits among Neolamarckia cadamba

\begin{tabular}{cccc}
\hline Cluster & Height $(\mathrm{m})$ & Girth at breast height $(\mathrm{cm})$ & Volume $\left(\mathrm{m}^{3}\right)$ \\
\hline I & 4.84 & 29.76 & 0.037 \\
II & 5.34 & 32.10 & 0.048 \\
III & 7.26 & 40.07 & 0.103 \\
IV & 5.85 & 33.50 & 0.057 \\
V & 7.38 & 43.41 & 0.118 \\
\hline
\end{tabular}

Table 8 Contribution of different growth traits to total divergence among Neolamarckia cadamba

\begin{tabular}{lcc}
\hline Character & No. of first rank & \% Contribution \\
\hline Height & 48 & 25.26 \\
Girth at Breast Height & 32 & 16.84 \\
Volume & 110 & 57.90 \\
Total & 190 & 100 \\
\hline
\end{tabular}

et al. 2001). The provenances of Parambikulam, Nilambur, Malayattur consistently recorded better biomass production and better relative growth (Jayasankar et al. 1999). All these studies registered a few genetic resources which lend support to the superiority of FCRIK17 progeny, witnessed in the current investigation. Genetic selection of rapid juvenile growth rate was also advocated as a means of improving competitive ability of forest trees (Gall \& Taft 1973, Steiner 1986) which extend the scope of selection of a progeny in the current study, based on superiority during the period under evaluation.

\section{Variability parameters}

The success of the tree improvement program depends on the variability present in the material and hence studies were conducted to characterise the variability existed among kadam genetic resources. In the present study, volume recorded highest phenotypic coefficient of variation and 
moderate genotypic coefficient of variation. Characters like tree height and gbh exhibited low to moderate genotypic and phenotypic coefficient of variation. Current findings are similar to studies in Melia dubia which showed low GCV and PCV for plant height, basal diameter and volume index (Kumar et al. 2013). Similarly, low GCV and PCV for height and collar diameter were also reported in Bambusa pallida (Singh \& Beniwal 1993).

In general, for all the traits, phenotypic coefficients of variations were higher than their respective genotypic ones. Such results are expected when the environmental variances are larger because phenotypic variances consist of genotypic and environmental variation. In other words, expression of the traits has been affected by the influence of the environmental factors as evidenced in Neem (Dhillon et al. 2003), Dalbergia sissoo (Dogra et al. 2005) and in progenies of Eucalyptus grandis (Subramanian et al. 1995).

\section{Heritability and genetic advance}

Heritability has an important place in tree improvement programme as it provides an index of the relative strength of heredity versus environment. It is also useful for ranking importance of each trait in the cross breeding programme. Heritability expresses the degree to which a character is influenced by heredity as compared to the environment.

Estimation of broad sense heritability for various characters showed moderate heritability for tree height (0.35), gbh (0.50) and volume (0.51). The results are on par with the studies carried out by Raymond (2002) on Eucalyptus globulus and Eucalyptus nutens which recorded low to moderate heritability for different genetic parameters. Low to moderate heritability was recorded for height and tree volume in $E$. grandis (Osorio et al. 2001) and for clean stem height and collar diameter in Eucalyptus tereticornis (Ginwal et al. 2004).

Volume registered high heritability as compared to gbh and height. Similar results were found in the studies of Hodge and White (1992) which registered moderate to high heritability for height, diameter and volume was found in Eucalyptus grandis and Pinus elliotti (Lambeth et al. 1994). Since height, gbh and volume showed moderate to high heritability percentage, the selection for these traits would be effective and improvement would be made through mass selection.

High heritability indicates the effectiveness of selection based on good phenotypic performance but does not necessarily mean a high genetic gain for particular traits. Heritability estimates, in the broad sense, will be reliable if accompanied by high genetic advance (Burton \& Devane 1953). In the present study, the trend of genetic advance as percent of mean was maximum in volume followed by gbh and height, indicating a wide scope of genetic improvement possibility in the species. The findings of the current study are in line with those of Ramachandra (1996) in Acacia catechu. Other research workers have also reported similar results in Terminalia arjuna (Srivastava et al. 1993), Grewia optiva (Sharma \& Sharma 1995) and also in Eucalyptus grandis (Subramanian et al. 1995) which lend support to the results of the current investigation.

In teak, low heritability estimates for height and GBH (Rao et al. 2001) and high heritability estimates for height (Anmol kumar et al. 1997) and moderate heritability estimate for growth attributes (Callister and Collins 2007) which indicated wider variation and extend support to the findings of this study.

\section{Determination of genetic diversity}

The nature and degree of genetic divergence in the seed sources is useful for classifying them into groups on the basis of their diversity, particularly when overlapping for one or more characters is frequent. The genetic divergence analysis also helps in identifying the desirable genotypes for improvement programme, presuming that genetic diversity would provide greater livelihood of promising genetic rearrangement. In the current study, genetic diversity existed among the 20 selected progenies of Kadam, assessed through $\mathrm{D}^{2}$ analysis, which resolved the 20 progenies into five clusters.

\section{Cluster composition}

Application of Mahalanobis statistics and Tocher's technique allowed grouping of the 20 Kadam progenies into five distinct clusters, indicating adequate genetic variability among the clusters under study. Among the five clusters, cluster III \& IV included the maximum of six genotypes each and cluster V included four genotypes. In Pinus wallichiana, 88 tree progenies were grouped into 
10 distinct clusters on the basis of Mahalanobis $\mathrm{D}^{2}$ statistic. A maximum number of genotypes (21) were grouped in cluster IV, followed by cluster III (18) and cluster X (14). Clusters V and VII consisted of 10 genotypes each followed by clusters I and VIII which included 8 and 4 genotypes, respectively. Cluster III, VI and IX were distinct and unique from others as each included only one genotype (Aslam et al. 2011). Similarly, 80 batches of teak had been grouped into eight clusters, of which group A formed the largest cluster containing 46 batches (Bagchi 2000).

In the present investigation, some clusters included genotypes from all the locations, while others included only a particularly unique and distinct genotype. It could be seen that the genotypes from different locations were grouped together to form a single major cluster, as evident in cluster III, and therefore the pattern of divergence was not dependent on geographic locations. These findings were in agreement with the results of Aslam et al. (2011) in Pinus wallichiana and suggested that all the genotypes from a given area may not necessarily form a single cluster. Thus, the pattern of divergence is not dependent on geographical nearness of the genotypes and such a pattern could be attributed to differences in the genetic make-up of the otherwise co-occurring genotypes (Chauhan \& Sehgal 2001).

In the present study, the highest intra-cluster distance was observed for cluster III (2.32) and the minimum for cluster I (0.01). Cluster I had minimum intra-cluster value indicating that genotype within the cluster was similar, while cluster III showed maximum intra-cluster $\mathrm{D}^{2}$ value followed by cluster IV (1.42), revealing the existence of diverse genotypes. The intra-cluster distance was much lower than inter-cluster one, suggesting heterogeneous and homogenous nature between and within clusters, respectively, and wide genetic diversity among the genotypes of different clusters than those of the same cluster. The data on inter-cluster distances and as per the performance of genotypes were used to select genetically diverse and silviculturally superior genotypes.

The genotypes, exceptionally good with respect to one or more characters, were desirable. A perusal of intra- and inter-cluster distances revealed that highest inter-cluster distance of 9.75 was between cluster I and V, followed by cluster I and III (7.30). Genotypes drawn from genetically diverse clusters could be particular significant in the production of high heterotic effect during hybridisation (Aslam et al. 2011). Such inter- and intra-cluster distance among Pinus gerardiana was also reported by Anil Kant et al. (2006) supporting the results of current conclusion.

\section{Contribution of traits towards genetic divergence}

In the present investigation, among the growth attributes, volume contributed maximum $(57.90 \%)$ towards genetic divergence followed by height and gbh. Paramathma (1992) reported similar results in six Eucalyptus species and twelve inter specific hybrids. Bagchi (2000) in T. grandis and Vennila (2009) in Eucalyptus also reported contribution of volume index along with other morphometric traits towards genetic divergence among the genotypes tested, which might be due to the existence of broader genetic base. Based on the current findings, the contribution of volume for genetic divergence indicated that the factor could be used as an index for Kadam tree improvement programme.

\section{CONGLUSIONS}

Kadam is one of the potential fast growing tree species amenable for various agroforestry systems but received little research attention towards improvement of the species. The current study is an intervention to resolve the issue through systematic progeny test program. The progenies differed significantly and exhibited the superiority progeny, FCRIK17, which is focused for immediate adoption. The studies on genetic estimates indicated that volume is the profound character for consideration towards kadam improvement program. Genetic diversity analysis indicated the existence of wide variation among the progenies, and extended scope towards further improving the species, both for biomass and wood quality.

\section{REFERENCE}

Anil-Kant, Vaishnu-Dutt \& Sharma DR. 2006. Genetic variability in phenotypic characters of Pinus gerardiana. Indian Forester 132: 681-690.

Anmol-Kumar MG, Gogate, Rajesh-Sharma \& Mandal AK. 1997. Genetic evaluation of teak clones of Allapalli region, Maharastra. Indian Forester 123: 187-189. 
Aslam-Mohd A, Zafar-Reshi \& SiddieI TO. 2011. Genetic divergence in half-sib progenies of Pinus wallichiana A.B. Jackson plus trees in the Kashmir Himalaya, India. Tropical Ecology 52: 201-208.

BAGCHI SK. 2000. Genetic divergence in Tectona grandis. Annals of Forestry 8: 25-37.

Burton GW \& Devane EW. 1953. Estimating heritability in Festuca aruandinacea from replicated clonal material. Agronomy Journal 45: 478-481.

Burton GW. 1952. Quantitative inheritance in grass. Proceedings of the Sixth International Grassland Congress 7: 277-283.

Callister AN \& Collins SL. 2007. Genetic parameter estimates in a clonally replicated progeny test of teak (Tectona grandis Linn. f.). Tree Genetics and Genomes. doi: 10.1007/s11295-007-0104-2.

Chauhan SK \& Sehgal RN. 2001. Genetic diversity among progenies of Himalayan long Pine. Indian Journal of Forestry 24: 65-71.

Dhillon RS, Bisla SS, Arya S \& Hooda MS. 2003. Genetic variation, heritability and correlations for growth parameters in Azadirachta indica. Annals of Forestry 11: 215-221.

Dogra AS, Nautiyal S, Nautiyal DP \& Singh G. 2005. Evaluation of field performance of 34 progenies of Dalbergia sissoo in Punjab. Annals of Forestry 13: 199-204.

GALL WR \& TAFT KA. 1973. Variation in height growth and flushing of Northern red oak (Quercus rubra L). Proceedings of the South for Tree Improvement Conference 12: 154-164.

Ginwal HS, Pradip Kumar, Sharma VK, Mandal AK \& HARWOOD CE. 2004. Genetic variability and early growth performance of Eucalyptus tereticornis Sm. in provenance cum progeny trails in India. Silvae Genetica 53: 148-153.

Ho WS, Pang SL, Tchin BL et al. 2012. Applications of genomics to plantation forestry with kelampayan in Sarawak. Pp 103-111 in Mohd-Effendi W et al. (eds) The Proceeding of the $4^{\text {th }}$ Regional Conference on Natural Resources in the Tropics, 2012 (NTrop4): Sustaining Tropical Natural Resources Through Innovations, Technologies and Practices. 19-20 September 2012, Sarawak.

Hodge GR \& White TL. 1992. Genetic parameter estimates for growth traits at different ages in slash pine and some implications for breeding. Silvae Genetica 41: 252-262.

Jayasankar S, Babu LC, Sudhakara K \& Kumar PD. 1999. Evaluation of provenance for seedling attributes in teak (Tectona grandis Linn. F) Silvae Genetica 48: 115-122.

Jна RK. 2012. Study of variability, associations and path analysis in poplar (Populus deltoids Bartr.ex Marsh). Journal of Sustainable Forestry 31: 185-204.

Johnson HW, Robinson HF \& Comstock RE. 1955. Estimation of genetic and environmental variability in soy bean. Agronomy Journal 47: 314-318.

Joker D. 2000. Neolamarckia cadamba (Roxb.) Bosser. Seed Leaflet 17: 2.

Kumar A. 2007. Growth performance and variability in different clones of Gmelina arborea (Roxb.). Silvae Genetica 56: 32-36.
Kumar P, Parthiban KT \& Sarvanan V. 2013. Genetic variations among open pollinated families of selected better trees in Melia dubia. Research Journal of Recent Sciences 2: 189-194.

LaKShmikantham D, RaWAT MS \& Kedharnath S. 1974. Half sib analysis of genetic variance in Teak. Journal of Genetics 34: 413-418.

LAmbeth C, Endo M \& Wright J. (1994). Genetic analysis of 16 clonal trials of Eucalyptus grandis and comparisons with seedling checks. Forest Science 40: 397-411.

LusH KI. 1940. Intrasite correlation and regression of spring on dams as a method of establishing heritability of characters. Proceedings of the American Society, Animal Production 33: 293-301.

Mahalanobis PC. 1928. On the need for standardisation in measurements on the living. Biometrika: 1-31.

Osorio LF, White TL \& Huber DA. 2001. Age trends of heritability and genotype-by-environment interactions for growth traits and wood density for clonal Eucalyptus grandis Hill ex Maiden. Silvae Genetica 50: 108-117.

Paramathma M. 1992. Studies on genetic inheritance and interspecific crosses of Eucalyptus. PhD thesis, Tamil Nadu Agricultural University, Coimbatore.

RAMACHANDRA NG. 1996. Provenance variation in seed and seedling parameters in Acacia catechu. Willd. PhD thesis, FRI Deemed University, Dehra Dun.

Rao PS, Venkaiah K, Murali V, Murti Ssn \& Sattar SA. 2001. Evaluation of international teak provenance trail plot in North East Andhra Pradesh. Indian Forester. 415-422.

RAYMOnd CA. 2002. Genetics of Eucalyptus wood properties. Annals of Forest Sciences 59: 525-531.

RaWAT MS, UnIYAL DP \& Sharma SL. 1998. Identification of provenances based on leaf morphology in Tectona grandis. Indian Forester 124: 248-251.

Sharma RK \& Sharma SS. 1995. Heritability and association analysis in Grewia optiva. Indian Forester 121: 318-320.

Singh NB \& Beniwal BS. 1993. Variability, heritability and genetic gain of some growth characters in Bambusa balcooa. Indian Forester 119: 205-210.

Srivastava DP, Srivastav PK, Goel AK \& Thangavelu K. 1993. Correlation and path coefficient studies in Terminalia arjuna. Annals of Forestry 1: 178-181.

Steiner KC. 1986. Integrating tree improvement with hard wood seedling production. Proceedings, North-Eartern Area Nurseryman's Congress 39: 24-30.

Subramanian KN, Mandal AK \& Nicodemus A. 1995. Genetic variability and character association in Eucalyptus grandis. Annals of Forestry 3: 134-137.

Syed M, Gupta VK \& Pandey HC. 2013. Studies of phenotypic and genetic variation in various growth characters in Neem (Azadirachata indica A. Juss) germplasm. Agricultural Science Research Journals 3: 72-78.

Tewari SK, Kohli RK, Arya KS \& Atal. 1996. Diagnostic survey of Shisham. Pp 53-55 in Kohli RK et al. (eds) Proceedings of the IUFRO-DNAES International Meeting: Resource Inventory Techniques to Support Agroforestry and Environment. HKT Publication, Chandigarh 53-55 .

Vennila S. 2009. Pulpwood traits, genetic and molecular characterization of Eucalyptus genetic resources. PhD thesis. Tamil Nadu Agricultural University, Coimbatore. 